\title{
Atividade antimicrobiana de óleos essenciais de condimentos frente a Staphylococcus spp isolados de mastite caprina
}

\author{
Antimicrobial activities of essential oils extracted from spices against Staphylococcus spp \\ isolated from goat mastitis
}

\section{Marcelo Dal Pozzo $^{\text {I* Julio Viégas }}{ }^{\mathrm{I}}$ Deise Flores Santurio ${ }^{\mathrm{II}}$ Luana Rossatto ${ }^{\mathrm{II}}$ Isaura Helena Soares ${ }^{\mathrm{II}}$ Sydney Hartz Alves ${ }^{\text {II }}$ Mateus Matiuzzi da Costa ${ }^{\text {III }}$}

RESUMO

Avaliou-se a atividade antimicrobiana dos óleos essenciais (OEs) de Origanum vulgare (orégano), Thymus vulgaris (tomilho), Lippia graveolens (lipia), Zingiber officinale (gengibre), Salvia officinalis (sálvia), Rosmarinus officinalis (alecrim) e Ocimum basilicum (manjericão), bem como de frações majoritárias carvacrol, timol, cinamaldeído e cineol frente a 33 isolados de Staphylococcus spp oriundos de rebanhos leiteiros caprinos. A concentração inibitória mínima (CIM) e a concentração bactericida mínima (CBM) foram determinadas por meio da técnica de microdiluição em caldo. Observou-se atividade antimicrobiana para os OEs de orégano, lípia e tomilho, bem como para as frações majoritárias de carvacrol, timol e cinamaldeído. A ordem decrescente de atividade foi orégano $=$ tomilho > lípia. As frações majoritárias carvacrol, timol e cinamaldeído evidenciaram melhor atividade do que os óleos essenciais e, dentre elas, carvacrol $e$ cinamaldeído foram mais ativas que o timol.

Palavras-chave: plantas medicinais, fitoterapia, antimicrobianos alternativos.

ABSTRACT

The antimicrobial activity of some essencial oils was evaluated as follows: Origanum vulgare (oregano), Thymus vulgaris (thyme), Lippia graveolens (Mexican oregano), Zingiber officinale (ginger), Salvia officinalis (sage), Rosmarinus officinalis (rosemary) and Ocimum basilicum (basil), as well as the majority constituents carvacrol, thymol, cinnamaldehyde and cineole against 33 Staphylococcus spp isolates from herds of dairy goats. The minimum inhibitory concentration (MIC) and the minimum bactericidal concentration $(M B C)$ were determined for each isolate by using broth microdilution method. Antimicrobial activity observed on the essencial oils of oregano, mexican oregano, thymus, well as to majoritary constituents of carvacrol, thymol and cinnamaldehyde. The descending order of antimicrobial activity were oregano $=$ thyme $>$ mexican oregano. The majority constituents carvacrol, thymol, cinnamaldehyde presented themselves more active than the verified by the essencial oils. The majority constituents, carvacrol and cinnomaldehyde were equally more active than thymol.

Key words: medicinal plants, phytotherapy, antimicrobial alternatives.

\section{INTRODUÇÃO}

O rebanho efetivo (cabeças) de caprinos no Brasil é estimado em 7,1 milhões de animais, sendo que aproximadamente $91 \%$ estão na região Nordeste (IBGE, 2006). A produção de leite de cabras desempenha papel relevante como fonte de proteínas e constitui-se em importante fator sócioeconômico para os pequenos produtores, através da utilização de seus subprodutos (LIMA, 2008). A falta de organizações de criadores, aliada à carência de assistência técnica especializada, além da precariedade do manejo higiênico-sanitário, são entraves que prejudicam o crescimento da atividade. Os problemas sanitários, nutricionais e manejo inadequado limitam o potencial produtivo destes animais (CHAPAVAL et al., 2009).

'Departamento de Zootecnia, Centro de Ciências Rurais (CCR), Universidade Federal de Santa Maria (UFSM), Sala 04, Prédio 78, Avenida Roraima, n.1000, Cidade Universitária, Bairro Camobi, 97105-900, Santa Maria, RS, Brasil. E-mail: marcelodalpozzo@yahoo.com.br.*Autor para correspondência.

"Departamento de Microbiologia e Parasitologia, Centro de Ciências da Saúde (CCS), UFSM, Santa Maria, RS, Brasil.

"I'Fundação Universidade Federal do Vale do São Francisco (UNIVASP), Petrolina, PE, Brasil. 
A mastite infecciosa é causada por uma ampla variedade de microrganismos. As bactérias dos gêneros Staphylococcus e Streptococcus são os principais microrganismos contagiosos, e estão relacionados com o descuido na higienização dos equipamentos de ordenha, anti-sepsia nos tetos e mãos do ordenhador. Há também agentes ambientais como as enterobactérias (Escherichia coli, Klesbsiella pneumoniae, Enterobacter aerogenes), Nocardia spp., Pseudomonas aeruginosa, fungos e algas (CONTRERAS et al., 2007). Um estudo realizado por BERGONIER et al. (2003) apontou S. aureus como o agente de maior prevalência em mastites clínicas ovinas e caprinas. Em relação às mastites subclínicas caprinas, BERGONIER et al. (2003) relata que as principais bactérias isoladas foram Staphylococcus coagulase negativa (71\% dos casos) e S. aureus (8\%).

A infusão intramamária de antibióticos é o método mais amplamente utilizado para o tratamento das afecções infecciosas da glândula mamária. Entretanto, as taxas de cura obtidas com antibióticos são, geralmente, insatisfatórias e dependem muito dos patógenos envolvidos (EBERHART et al., 1986). O uso de agentes antibacterianos em animais, incluindo os casos de mastites, pode determinar a emergência de bactérias resistentes (WHO, 2003 e ZAFALON et al. 2008), constituindo-se em fonte de resíduos de antibióticos no leite. (ERSKINE et al., 2003). Frente a este cenário, alternativas terapêuticas têm sido pesquisadas destacando-se a própolis e derivados de plantas como agentes antimicrobianos (VARGAS et al., 2004; BASKARAN et al., 2009).

Os Óleos Essenciais (OEs), derivados de plantas utilizadas como condimentos, representam um grupo de antimicrobianos naturais tradicionalmente usados em alimentos para acentuar gosto ou aroma destes. Constituem-se em complexas misturas de substâncias voláteis (SIMÕES \& SPITZER, 2000) cujos componentes incluem hidrocarbonetos terpênicos, álcoois simples, aldeídos, cetonas, fenóis, ésteres, ácidos orgânicos fixos, em diferentes concentrações, em que um composto farmacologicamente ativo é majoritário. Assim, no orégano, destaca-se o carvacrol (3 a 17\%); no tomilho, o timol (40\%) (FARMACOPEA ITALIANA, 1998). Os OEs extraídos de orégano e tomilho têm potencial antimicrobiano significativo (BURT, 2004; KALEMBA et al., 2002) frente a bactérias Gram positivas, Gram negativas e fungos (SANTURIO et al., 2007; MAYAUD et al., 2008). Nesse contexto, é oportuno avaliar com técnicas microbiológicas a atividade de óleos essenciais sobre Staphylococcus spp., um dos principais patógenos causador de mastites em rebanhos leiteiros.
O presente estudo objetiva avaliar a atividade antimicrobiana dos OEs extraídos de lípia, manjericão, orégano, alecrim, sálvia, tomilho, gengibre e das frações majoritárias carvacrol, timol, cinamaldeído e cineol, frente à Staphylococcus spp. de origem caprina com variados perfis de resistência a agentes antimicrobianos de uso rotineiro.

\section{MATERIAL E MÉTODOS}

Microrganismos

Foram estudados 33 isolados de mastite caprina, provenientes do Laboratório de Bacteriologia Veterinária da Universidade Federal do Vale do São Francisco. Os isolados foram identificados como: 1) Staphylococcus $\mathrm{sp}$. coagulase positiva $(\mathrm{n}=6) ; 2)$ Staphylococcus sp. coagulase negativa $(\mathrm{n}=27)$. A cepa padrão S. aureus ATCC 29213 foi utilizada (controle positivo) e também foi utilizado uma linhagem de Salmonella enterica (sabidamente sensível) utilizada por SANTURIO et al. (2007).

Teste de suscetibilidade aos antimicrobianos

Os testes de suscetibilidade aos antimicrobianos foram realizados pelo método de difusão em ágar (CLSI M31-A3; 2008), incluindo-se os seguintes agentes: ceftiofur $(30 \mu \mathrm{g})(\mathrm{CEF})$, penicilina (10U)(PEN), ampicilina (10 $\mu$ g)(AMP), cefalotina $(30 \mu \mathrm{g})(\mathrm{CEFA})$, oxacilina $(1 \mu \mathrm{g})(\mathrm{OXA})$, eritromicina $(15 \mu \mathrm{g})(\mathrm{ERI})$, tetraciclina $(30 \mu \mathrm{g})(\mathrm{TET})$. Com base nesses testes, os isolados foram subagrupadas de acordo com os seguintes perfis de resistência: 1) isolados não resistentes; 2) isolados resistentes à tetraciclina; 3) isolados resistentes à tetraciclina e penicilina; 4) isolados resistentes à eritromicina e tetraciclina; 5) isolados resistentes à eritromicina e penicilina; 6) isolados resistentes à eritromicina, penicilina e tetraciclina; 7) isolados resistentes à penicilina, oxacilina , ampicilina , cefalotina e tetraciclina; 8) isolados resistentes à eritromicina, oxacilina, penicilina, cefalotina, ampicilina e tetraciclina (Tabela 1).

Óleos essenciais e frações majoritárias

Foram avaliados os óleos essenciais de: Origanum vulgare, Thymus vulgaris, Lippia graveolens, Zingiber officinale, Salvia officinalis, Rosmarinus officinalis e Ocimum basilicum, bem como as frações majoritárias carvacrol, timol, cinamaldeído e cineol. A tabela 2 apresenta suas composições. As frações majoritárias foram adquiridas da empresa Essential7. com; Roewell, New Mexico, USA, e da Acros Organics; Fair Lawn, NJ, USA; os óleos essenciais cuja composição foram determinadas previamente por POZZATTI et al. (2010). 
Tabela 1 - Relação de óleos essenciais e frações majoritárias utilizados no estudo, com as respectivas composições.

\begin{tabular}{|c|c|c|}
\hline OES $^{*}$ e Frações majoritárias ${ }^{* *}$ & Plantas condimentares (espécie) & Composição (Fração majoritária \%) \\
\hline Orégano $^{*}$ & Origanum vulgare & carvacrol $(92,6)$ \\
\hline Tomilho* & Thymus vulgaris & $\gamma$-terpineno (64) \\
\hline Lípia $^{*}$ & Lippia graveolens & carvacrol $(56,8)$ e $o$-cimeno $(32,2)$ \\
\hline Alecrim $^{*}$ & Rosmarinus officinalis $\mathbf{L}$. & 1,8 -cineol $(28,6)$ e cânfora $(26,31)$ \\
\hline Sálvia $^{*}$ & Salvia officinalis $\mathbf{L}$. & cis-tujona $(40,6)$ \\
\hline Manjericão* & Ocimum basilicum $\mathbf{L}$. & linalol $(32,2)$ e 1,8 -cineol $(23,6)$ \\
\hline Gengibre ${ }^{*}$ & Zingiber officinale & zingibereno $(20,8)$ \\
\hline Carvacrol $^{* *}$ & - & Carvacrol $(99,5)$ \\
\hline Timol $^{* *}$ & - & Timol $(99,0)$ \\
\hline Cinamaldeído $^{* *}$ & - & cinamaldeído $(99,0)$ \\
\hline Cineol $^{* *}$ & - & cineol $(97,0)$ \\
\hline
\end{tabular}

*Óleos Essenciais adquiridos Essential7. com Roewell, New Mexico, USA, cujas composições foram determinadas previamente por POZZATTI et al. 2010; ${ }^{* *}$ Frações majoritárias adquiridas da Acros Organics; Fair Lawn, NJ, USA.

Determinação das concentrações inibitórias mínimas Após pesagem de $1 \mathrm{~g}$, cada $\mathrm{OE}$ foi diluído em metanol até atingir a concentração de $640 \mathrm{mg} \mathrm{ml}^{-1}$ (Solução I). A seguir, diluiu-se a 1:100 em Caldo MullerHinton, obtendo-se a concentração de $6400 \mu \mathrm{g} \mathrm{ml}^{-1}$ (Solução II).

As CIMs (menor concentração capaz de inibir o crescimento bacteriano) foram determinadas com base no documento M31-A3(CLSI, 2008). Inicialmente, foi realizada a distribuição de $100 \mu \mathrm{L}$ de Caldo Muller-Hinton nos poços de uma placa de microtitulação, excetuando-se os poços da primeira coluna. Somente nestes da primeira coluna, eram depositados $200 \mu \mathrm{L}$ da Solução II; a seguir, volumes de $100 \mu \mathrm{L}$ foram transferidos dos poços da primeira coluna para os da segunda coluna e assim, sucessivamente, obtendo-se concentrações finais de: 6400, 3200, 1600, $800,400,200,100 \mu \mathrm{g} \mathrm{ml}^{-1}$. O inóculo foi preparado, a partir de colônias desenvolvidas no ágar Muller-
Hinton, obtendo-se uma suspensão bacteriana em salina, com turvação equivalente ao tubo 0,5 da Escala Mac Farland (1x108UFC $\left.\mathrm{ml}^{-1}\right)$. Dessa suspensão, inoculou-se $10 \mu \mathrm{l}(1 \times 105)$ em cada poço contendo os óleos essenciais incorporados ao caldo Muller-Hinton. As microplacas foram incubadas a $35^{\circ} \mathrm{C}$ por $24 \mathrm{~h}$, em condições de aerobiose. A determinação das CIMs consistiu em registrar a menor concentração do óleo essencial ou fração majoritária capaz de causar inibição total do crescimento. Esses ensaios foram realizados em triplicata.

Determinação das concentrações bactericidas mínimas Definida como a menor concentração dos óleos essenciais capaz de causar a morte do inóculo, foi determinada a partir dos poços em que, após $24 \mathrm{~h}$ de incubação, não havia crescimento bacteriano visível. Destes transferiu-se uma alíquota de $10 \mu \mathrm{l}$ para a superfície do Ágar Muller-Hinton, o qual foi incubado

Tabela 2 - Atividade antimicrobiana dos óleos essenciais de orégano, lípia, tomilho e das frações majoritárias carvacrol, timol e cinamaldeído frente à Staphylococcus spp isolados de mastite caprina.

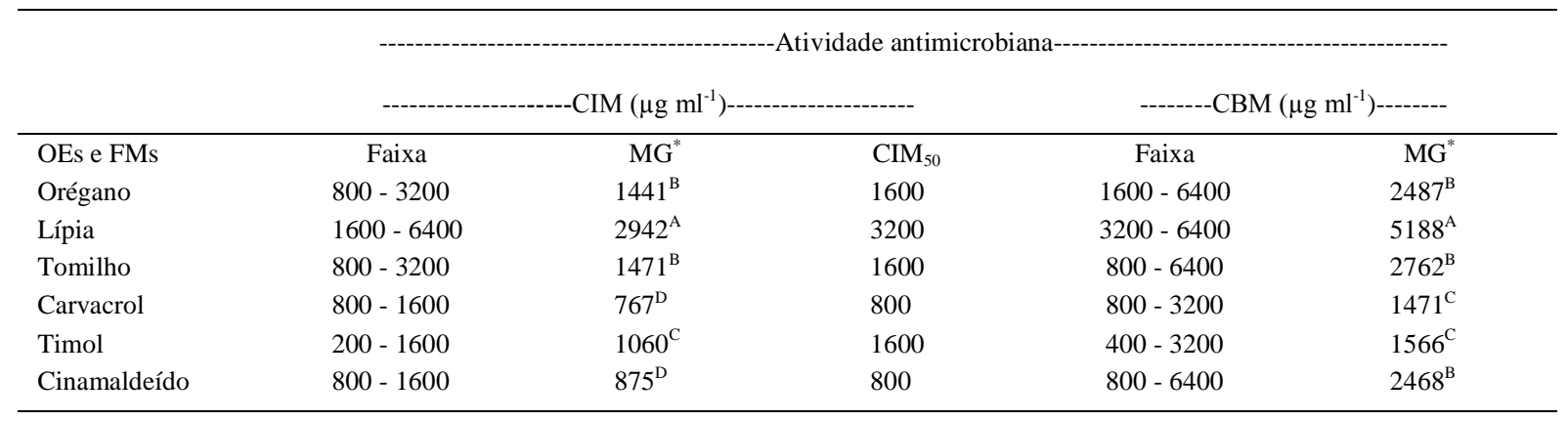

CIM = Concentração Inibitória Mínima; CBM = Concentração Bactericida Mínima; CIM $_{50}=$ Concentração Inibitória Mínima capaz de inibir $50 \%$ dos isolados * MG = Média Geométrica, em que letras iguais na mesma coluna indicam atividade antimicrobiana similar 
a $35^{\circ} \mathrm{C}$ por $24 \mathrm{~h}$. A seguir, observou-se o crescimento bacteriano, registrando-se a menor concentração dos OEs ou frações majoritárias que não evidenciava crescimento bacteriano. Esses ensaios foram realizados em triplicata.

\section{Análise Estatística}

O teste de Mann Whitney foi empregado para comparar duas amostras independentes, visando a observar se os diferentes grupos em estudo apresentavam perfis de suscetibilidade semelhantes ou não, frente a determinado óleo essencial ou fração majoritária.

\section{RESULTADOS E DISCUSSÃO}

Os isolados evidenciaram susceptibilidade variável frente às concentrações dos óleos essenciais $(\mathrm{OEs})$ e frente às frações majoritárias (FMs). As médias geométricas para as Concentrações Inibitórias Mínimas (CIMs) e Concentrações Bactericidas Mínimas (CBMs) foram: lípia [CIM=2942 $\mu \mathrm{g} \mathrm{ml}^{-1}$ e CBM $\left.=5188 \mu \mathrm{g} \mathrm{ml}^{-1}\right]$; orégano $\left[1441 \mu \mathrm{g} \mathrm{ml}^{-1}\right.$ e CBM $=2487 \mu \mathrm{g} \mathrm{ml}^{-1}$; tomilho $\left[\mathrm{CIM}=1471 \mu \mathrm{g} \mathrm{ml}^{-1}\right.$ e CBM $\left.=2762 \mu \mathrm{g} \mathrm{ml}^{-1}\right]$; carvacrol

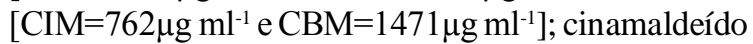
$\left[\mathrm{CIM}=875 \mu \mathrm{g} \mathrm{ml}^{-1}\right.$ e $\left.\mathrm{CBM}=2468 \mu \mathrm{g} \mathrm{ml}^{-1}\right]$ e timol $\left[\mathrm{CIM}=1060 \mu \mathrm{g} \mathrm{ml}^{-1}\right.$ e CBM=1566 $\mu \mathrm{g} \mathrm{ml}^{-1}$. (Tabela 3). Considerando-se os subgrupos pela coagulase, os Staphylococcus coagulase positiva e os Staphylococcus coagulase negativa apresentaram perfis de sensibilidade similares $(\mathrm{P}>0,05)$ frente aos $\mathrm{OEs}$ ou fração majoritária testados.

Considerando-se as médias geométricas das CIMs, os óleos essenciais de orégano e tomilho foram igualmente os mais ativos. As frações majoritárias foram mais ativas que os óleos essenciais $(\mathrm{P}<0,05)$, com exceção das CBMs do cinamaldeído, que foram similares às $\mathrm{CBMs}$ dos óleos essenciais de orégano $\mathrm{e}$ tomilho. Com base nas CIMs, as frações majoritárias carvacrol e cinamaldeído foram igualmente mais ativas que o timol $(\mathrm{P}<0,05)$.

Com base no documento emitido pela World Health Organization (WHO, 2003), a emergência da resistência de Staphylococcus aos agentes antibacterianos constitui-se numa dupla ameaça ao homem e aos animais, sendo decorrente do intenso e indiscriminado uso dessa bactéria em medicina humana e veterinária. No presente estudo, os OEs e suas frações majoritárias evidenciaram atividades variáveis em função da susceptibilidade dos isolados. Ao analisarmos as atividades dos OEs sobre os subgrupos correspondentes aos perfis de resistência (1 a 8; Tabela 1) não se detectou relação entre perfil de resistência aos antibacterianos com variação na susceptibilidade aos OEs e frações majoritárias. Estes achados estão de acordo com NOSTRO et al. (2004) que também não evidenciaram diferenças de susceptibilidade de Staphylococcus sensíveis à meticilina (MSS) ou resistentes à meticilina (MRSA) frente ao carvacrol e timol.

A maior concentração de carvacrol e timol nos OEs explicam a maior atividade antimicrobiana de alguns deles (NOSTRO et al., 2007). SARTORATTO et al. (2004) relataram atividade do OE de manjericão frente a isolados de Staphylococcus aureus. FU et al. (2007) verificaram atividade do $\mathrm{OE}$ de alecrim frente a Staphylococcus epidermides ATCC 12228 e Staphylococcus aureus ATCC 6538. DALAMARE et al. (2007) observaram atividade do óleo essencial de sálvia frente a alguns isolados de Staphylococcus spp.

Tabela 3 - Relações entre o perfil de resistência de Staphylococcus sp a antimicrobianos e a susceptibilidade a óleos essenciais e frações majoritárias.

\begin{tabular}{|c|c|c|c|c|c|c|c|}
\hline \multirow{2}{*}{ Sub Grupos (n) } & \multirow{2}{*}{ Perfil deresistência } & \multirow[b]{2}{*}{ Ov } & \multicolumn{4}{|c|}{ 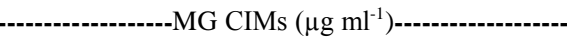 } & \multirow[b]{2}{*}{$\mathrm{tm}$} \\
\hline & & & $\operatorname{Lg}$ & $\mathrm{Tv}$ & $\mathrm{cv}$ & $\mathrm{cn}$ & \\
\hline $1(8)$ & não resistente & 1467,2 & 2934,4 & 1345,4 & 733,6 & 800,0 & 1345,4 \\
\hline 2(2) & TET & 1200,0 & 3200,0 & 1600,0 & 800,0 & 800,0 & 1200,0 \\
\hline $3(10)$ & TET-PEN & 1392,8 & 2785,7 & 1392,8 & 857,4 & 984,9 & 1131,3 \\
\hline $4(2)$ & ERI-TET & 1200,0 & 3200,0 & 1600,0 & 800,0 & 800,0 & 1200,0 \\
\hline $5(2)$ & ERI-PEN & 1600,0 & 3200,0 & 1200,0 & 600,0 & 1200,0 & 1200,0 \\
\hline $6(5)$ & ERI-PEN-TET & 1600,0 & 2785,7 & 2111,2 & 696,4 & 800,0 & 696,4 \\
\hline $7(3)$ & PEN-OXA-AMP-CEFA-TET & 1269,9 & 3200,0 & 1269,9 & 800,0 & 800,0 & 1007,9 \\
\hline $8(1)$ & ERI-OXA-PEN-CEFA-AMP-TET & 3200,0 & 3200,0 & 1600,0 & 800,0 & 800,0 & 800,0 \\
\hline
\end{tabular}

TET=tetraciclina; PEN=penicilina; ERI=eritromicina; OXA=oxacilina; $\mathrm{AMP}=$ ampicilina; $\mathrm{CEFA=cefalotina;} \mathrm{MG} \mathrm{CIMs} \mathrm{=} \mathrm{Média} \mathrm{Geométrica}$ das Concentrações Inibitórias Mínimas; (n) número de isolados; Ov = Oreganum vulgare $; \mathrm{Lg}=$ Lippia graveolens; $\mathrm{Tv}=$ Thymus vulgaris; $\mathrm{cv}=\mathrm{carvacrol} ; \mathrm{cn}=$ cinamaldeído; $\mathrm{tm}=$ timol. 
HENDRY et al. (2009) encontraram atividade do cineol frente a isolados de Staphylococcus aureus, porém a atividade foi inferior ao óleo essencial de eucalipto com $81 \%$ de cineol. De modo contrário a esses autores, no presente estudo, os OEs de gengibre, manjericão, alecrim, sálvia e a fração majoritária cineol não evidenciaram atividade antibacteriana frente aos microrganismos avaliados.

As comparações de nossos resultados com estudos similares devem ser cautelosas, uma vez que a grande maioria dos estudos emprega a técnica de difusão em ágar, fornecendo resultados referentes ao diâmetro de inibição, expressos em milímetros; mesmo os estudos de microdiluição em caldo, na grande maioria dos casos, não seguem procedimentos padronizados, como os aqui empregados.

Finalmente, este estudo permitiu evidenciar a especificidade da atividade de alguns óleos essenciais sobre isolados de Staphylococcus spp. Os resultados sinalizam para uma futura possibilidade de utilização dos óleos essenciais no controle da mastite bacteriana em caprinos. Estudos adicionais abordando o sinergismo entre óleos essenciais, frações majoritárias e agentes antibacterianos são fundamentais para o desenvolvimento de produtos alternativos no tratamento das mastites.

\section{CONCLUSÃO}

Este estudo permitiu concluir que: 1) os óleos essenciais de orégano, tomilho, lípia; bem como as frações majoritárias de cinamaldeído, timol e carvacrol evidenciaram significativa atividade antimicrobiana; 2) os óleos essenciais de orégano e tomilho apresentaram atividades antimicrobianas (CIMs e CBMs) similares e superiores ao óleo essencial de lípia; 3) as frações majoritárias evidenciaram maior atividade antimicrobiana do que os óleos essenciais; 4) o carvacrol e cinamaldeído apresentaram pequenas variações nas suas atividades inibitórias; no entanto a atividade bactericida do cinamaldeído foi significativamente inferior a do timol e carvacrol; 5) a ausência de relação entre o perfil de resistência de Staphylococcus aos antibacterianos com as variações na susceptibilidade aos OEs e frações majoritárias constitui-se num indicador da boa atividade destes produtos mesmo sobre bactérias, com marcado perfil de resitência, fato que merece prospecções futuras.

\section{REFERÊNCIAS}

BASKARAN, A.S. et al. Antibacterial effect of plant-derived antimicrobials on major bacterial mastitis pathogens in vitro. Journal of Dairy Science, v.92, n.4, p.1423-1429, 2009.
Disponível em: <http://download.journals.elsevierhealth.com/ pdfs/journals/0022-0302/PIIS0022030209704539.pdf>. Acesso em: 28 jan. 2011. doi: 10.3168/jds.2008-1384.

BERGONIER, D. et al. Mastitis of dairy small ruminants. Veterinary Research, v.34, p.689-716, 2003. Disponível em: < h t t p :// w w w. vet res.org/i ndex.ph p ? option $=$ com_article $\&$ a c cess $=$ doi $\&$ doi $=10.1051 /$ vetres:2003030\&Itemid=129>. Acesso em: fev. 2011. doi: 10.1051/vetres:2003030.

BURT, S. Essential oils: their antibacterial properties and potential applications in foods-a review. International Journal of Food Microbiol, v.94, n.3, p.223-253, 2004. Disponível em: <http:// onlinelibrary.wiley.com/doi/10.1046/j.1472-65X.2003.01285.x/ pdf $>$. Acesso em: 28 jan. 2011. doi: 10.1046/j.1472765X.2003.01285.x.

Clinical and Laboratory Standards Institute (CLSI). Antimicrobial disk and dilution susceptibility tests for bacteria isolated from animals; Approved Standard. 3.ed. Wayne, PA, 2008. (CLSI document M31-A3 Clinical and Laboratory Standards Institute).

CHAPAVAL, L. et al. Controle dos casos de mastite e da artrite encefalite caprina com a utilização de boas práticas agropecuárias: uso de procedimentos operacionais e instruções de trabalho no setor leiteiro da Embrapa caprinos e ovinos. Embrapa, 2009. 18p. (Documentos). Acesso em: 26 nov. 2010. Online. Disponível em: <http:// www.cnpc.embrapa.br/doc86.pdf $>$.

CONTRERAS, A. et al. Mastitis in small ruminants. Small Ruminant Research, v.68, p.145-163, 2007. Disponível em: <http://dx.doi.org/10.1016/j.smallrumres.2006.09.011>. Acesso em fev. 2011. doi: 10.1016/j.smallrumres.2006.09.011.

DELAMARE, A.P.L. et al. Antibacterial activity of the essential oils of Salvia ofcinalis L. and Salvia triloba L. cultivated in South Brazil. Food Chemistry, v.100, p.603-608, 2007. Disponível em: <http://dx.doi.org/10.1016/j.foodchem.2005.09.078>. Acesso em: 28 jan. 2011. doi: 10.1016/j.foodchem.2005.09.078.

EBERHART, R.J. Management of dry cows to reduce mastitis. Journal of Dairy Science, v.69, n.6, p.17211732, 1986. Disponível em: <http://dx.doi.org/10.3168/ jds.S0022-0302(86)80591-4>. Acesso em 01 fev. 2011. doi: 10.3168/jds.S0022-0302(86)80591-4.

ERSKINE, R.J. et al. Mastitis therapy and pharmacology. Veterinary Clinics of North America: Food Animal Practice, v.19, p.109-138, 2003. Disponível em: <http:// download.journals.elsevierhealth.com/pdfs/journals/ 07490720/PIIS0749072002000671.pdf>. Acesso em $01 \mathrm{fev}$. 2011. doi:10.1016/S0749-0720(02)00067-1.

FARMACOPEA UFFICIALE DELLA REPUBLICA ITALIANA. 10.ed. Roma: Instituto Poligrafico e Zecco dello Stato, 1998. V.I, p.206-210.

FU, Y. et al. Antimicrobial activity of clove and rosemary essential oils alone and in combination. Phytother Research, v.21, n.10, p.989-994, 2007. Disponível em: <http:// onlinelibrary.wiley.com/doi/10.1002/ptr.2179/ abstract;jsessionid=1A91415B394DF345F55DB80829EBB5E B.d03t01>. Acesso em 01 fev. 2011. doi: 10.1002/ptr.2179. 
HENDRY, E.R. et al. Antimicrobial efficacy of eucalyptus oil and 1,8-cineole alone and in combination with chlorhexidine digluconate against microorganisms grown in planktonic and biofilm cultures. Journal Antimicrobial Chemotherapy, v.64, n.6, p.1219-1225, 2009. Disponível em: <http:// jac.oxfordjournals.org/content/64/6/1219.long >. Acesso em: 01 fev. 2011. doi:10.1093/jac/dkp362.

INSTITUTO BRASILEIRO DE GEOGRAFIA E ESTATÍSTICA - IBGE. Censo Agropecuário (2006). Acesso em: 20 nov. 2010. Online. Disponível em: 〈http://www.sidra.ibge.gov.br>.

KALEMBA, D. et al. Antimicrobial properties of the essential oil of Artemisia asiatica Nakai. Phytotherapy Research, v.16, n.3, p.288-291, 2002. Disponível em: <http:// onlinelibrary.wiley.com/doi/10.1002/ptr.856/abstract>. Acesso em: 01 fev. 2011. doi: 10.1002/ptr.856.

LIMA, R.A.S. Distribuição do rebanho caprino no brasil nos anos 1995/96 e 2006. In: CONGRESSO DA SOCIEDADE BRASILEIRA DE ECONOMIA, ADMINISTRAÇÃO E SOCIOLOGIA RURAL, 46., 2008, Rio Branco, Acre. Acesso em: 25 nov. 2010. Online. Disponível em: <http:// www.sober.org.br/palestra/9/769.pdf>.

MAYAUD, L. et al. Comparison of bacteriostatic and bactericidal activity of 13 essential oils against strains with varying sensitivity to antibiotics. Letters in Applied Microbiology, v.47, p.167-173, 2008. Disponível em: <http:/ /onlinelibrary.wiley.com/doi/ $10.1111 /$ j. 1472 765X.2008.02406.x/abstract>. Acesso em: 01 fev. 2011. doi: $10.1111 / \mathrm{j} .1472-765 X .2008 .02406 . x$.

NOSTRO, A. et al. Susceptibility of methicillin-resistant staphylococci to oregano essential oil, carvacrol and thymol. FEMS Microbiol Letters, v.230, n.2, p.191-195, 2004. Disponível em: <http://onlinelibrary.wiley.com/doi/10.1016/ S0378-1097(03)00890-5/abstract>. Acesso em: 01 fev. 2011. doi: 10.1016/S0378-1097(03)00890-5.

NOSTRO, A. et al. Effects of oregano, carvacrol and thymol on Staphylococcus aureus and Staphylococcus epidermidis biofilms. Journal of Medical Microbiology, n.56, p.519523, 2007. Disponível em: <http://jmm.sgmjournals.org/cgi/ content/full/56/4/519>. Acesso em: 01 fev. 2011. doi: 10.1099/ jmm.0.46804-0.
POZZATTI, P. et al. Comparison of the susceptibilities of clinical isolates of Candida albicans and Candida dubliniensis to essential oils. Mycoses, v.53, p.12-15, 2010. Disponível em: <http:// onlinelibrary.wiley.com/doi/10.1111/j.1439-0507.2008.01643.x/ abstract>. Acesso em: 20 jan. 2011. doi: 10.1111/j.14390507.2008.01643.x.

SANTURIO, J. et al. Atividade antimicrobiana dos óleos essenciais de orégano, tomilho e canela frente a sorovares de Salmonella enterica de origem avícola. Ciência Rural, v.37, n.3, p.803-808, 2007. Disponível em: <http://www.scielo.br/ pdf/cr/v37n3/a31v37n3.pdf $>$. Acesso em: 28 de jan. 2011. doi: 10.1590/S0103-84782007000300031.

SARTORATTO, A. et al. Composition and antimicrobial activity of essential oils from aromatic plants used in Brazil. Brazilian Journal of Microbiology, v.35, p.275-280, 2004. Disponível em: <http:// www.scielo.br/scielo.php? script=sci_arttext $\&$ pid $=$ S151783822004000300001 >. Acesso em: 01 fev. 2011. doi: 10.1590/ S1517-83822004000300001.

SIMÕES, C.M.O.; SPITZER, V. Óleos voláteis. In: SIMÕES, C.M.O. et al. Farmacognosia: da planta ao medicamento. Porto Alegre/Florianópolis: UFRGS/UFSC, 2000. Cap.18.

VARGAS, A.C. et al. Alcoholic propolis extract: antimicrobial activity. Ciência Rural, v.34, n.1, p.159-163, 2004. Disponível em: <http://www.scielo.br/scielo.php?pid=s0103$84782004000100024 \&$ script $=$ sci_arttext $>$. Acesso em: 01 fev. 2011. doi: 10.1590/S0103-84782004000100024.

ZAFALON et al. Investigação de perfis de resistência aos antimicrobianos em Staphylococcus aureus isolados na ordenha de vacas em lactação. Revista do Instituto Adolfo Lutz, v.2, p.118-125, 2008. Disponível em: <http://revista.ial.sp.gov.br/ index.php?option $=$ com_remository \&Itemid $=27 \&$ func $=$ startdow n\&id=402>. Acesso em: fev. 2011.

WORLD HEALTH ORGANIZATION (WHO). Joint FAO/ OIE/WHO Expert Workshop on Non-Human Antimicrobial Usage and Antimicrobial Resistance: Scientific Assessment. Presented in Geneva, Switzerland, Dec. 2003. Acesso em: 24 nov. 2010. Online. Disponível em: <www.who.int/foodsafety/micro/meetings/nov2003/en/>. 